\title{
On Supernatural Miracles and Laws of Nature
}

Joseph Berkovitz

IHPST, University of Toronto

\begin{abstract}
Robert Larmer and Alvin Plantinga have argued that modern physics is compatible with the idea that the physical universe is open to God's supernatural action and that such action would not involve any violation of laws of nature. Thus, they have concluded that supernatural miracles are compatible with modern science. I argue that their line of reasoning is based on an incorrect interpretation of conservation laws and that supernatural miracles would involve violations of laws of nature.
\end{abstract}

Keywords: supernatural miracles, science, laws of nature, conservation principles

\section{Larmer's argument}

Robert Larmer considers three general models of divine agency: occasionalism, deism, and supernaturalism. Each of these models proposes a different understanding of miracles. Larmer argues that the concept of miracle is properly located within the supernatural model of divine agency and that the concept of supernatural miracle is not at odds with science. ${ }^{1}$

In the supernatural model, "the entities that make up nature have ... certain properties and causal powers. The interaction of these entities, that is to say secondary causes, gives rise to a regular order of nature. Most events within nature are explicable by reference to the operation of these secondary causes upon one another ... God, however, can directly act upon the created entities that make up nature so as to produce events that are not wholly explicable in terms of the operation of secondary causes. Such events would, in the supernaturalist's view, be properly termed miracles inasmuch as they constitute divine interventions into the natural order."

The common view is that it is impossible to reconcile the supernatural model of miracles with science because supernatural miracles would violate laws of nature. Larmer argues that in major philosophical accounts of laws of nature, the idea that laws of nature could be violated does not make sense as such laws are supposed to be exceptionless. While this seems to preclude any attempt to reconcile supernatural miracles with science, Larmer argues that supernatural miracles do not require a violation of laws of nature. The argument is basically the following. In performing miracles, God creates facts in a supernatural way, but this kind of creation does not entail the violation of laws of nature because laws of nature by themselves do not entail particular facts. Only when such laws are conjoined with particular facts do they entail other particular facts. Thus, laws of nature do not exclude the possibility of facts being created by divine intervention, and accordingly such intervention does not entail their violation.

It is tempting to object to this line of reasoning that supernatural intervention would require the violation of the principle of conservation of energy. But Larmer replies that such objection rests on a conflation of two different statements of the principle: (i) 
Energy can neither be created nor destroyed; (ii) In an isolated system the total amount of energy remains constant. Larmer notes that "it is routinely assumed that these two statements are logically equivalent" and he contends that "this assumption is false." $\mathrm{He}$ argues that the former statement of the principle of conservation of energy entails the latter but not vice versa and that the former statement involves a greater ontological commitment than the latter. ${ }^{4}$ Larmer holds that "the significance of this distinction is considerable. Theists cannot accept the claim that energy can be neither created nor destroyed, since it rules out not only miracles but also creation ex nihilo. Theists can, however, accept the claim that energy is conserved in an isolated system. They reject not the well-evidenced scientific claim that energy is conserved in an isolated system but the speculative metaphysical claim that nature is an isolated system not open to the causal influence of God. In short, they are in a position to affirm the principle when it is formulated as a scientific law and not as a metaphysical commitment that excludes the possibility of theism.",

\section{On supernatural miracles and laws of nature}

I am not acquainted with the literature on models of miracles in Christian theology. I am more familiar with the Hebrew Bible, and I find that the supernatural model of miracles provides a straightforward reading of miracles there. I also agree with Larmer that (ii) is the more supported reading of the law of conservation of energy, and I find (i) hopelessly vague. Larmer says that (i) is a metaphysical commitment, whereas (ii) is a scientific law, and he seems to suggest that (ii) could be tested empirically when he says that "all that any experiment can show is that energy was conserved in an isolated system on a particular occasion or series of occasions." I disagree with the distinction that Larmer seems to make between scientific law and metaphysical commitment. Both (i) and (ii) are metaphysical commitments. And although (ii) is more supported than (i), neither of them could simply be established or undermined by experiment. In fact, rather than being tested by experiments, (ii) is often used to analyze experimental results. For example, (ii) entails that if the energy of a physical system is not conserved, the system must have some physical interactions with its physical environment that account for the change in its energy. Similar considerations apply to other conservation laws, such as the conservation of linear and angular momenta. Finally, I agree with Larmer that laws of nature alone do not entail particular facts (though, as we shall see below, they often exclude the possibility of certain facts). Yet, I will argue that this characteristic of laws of nature does not ease the tension between the supernatural model of miracles and modern science and that Larmer's attempt to defuse this tension fails. Larmer's reasoning is based on an incorrect understanding of conservation principles. Larmer takes the principle of conservation of energy to apply only to causally isolated systems, and accordingly he is committed to the view that the principle has implications only for systems that resemble isolated systems. ${ }^{7}$ Now, actual subsystems of the universe are not isolated, and in Larmer's account of miracles the entire physical universe is also not an isolated system. ${ }^{8}$ Thus, Larmer is committed to the view that conservation principles are inapplicable to many (if not all) actual systems. Yet, as we shall see below, these principles have implications for all actual physical systems, and these implications render the supernatural model of miracles incompatible with modern physics. 
To make the discussion less abstract, I will refer to a famous miracle in the Book of Joshua, where in the battle with the Amorites Joshua asks God to prolong the daylight. The background to Joshua's miracle is that the Israelites are in the process of taking possession of the southern part of the Land of Canaan with Joshua as their leader. The city of Gibeon, north of Jerusalem, has just made peace with the Israelites in order to avoid the faith of the city-states of A'i and Jericho. This prompts the Amorite city-states in the area to initiate attack on Gibeon, which in turn asks Joshua for help. Joshua and his army march all night from Gilgal, near the Jordan River, to Gibeon and attack in early morning. The attack is very successful, but time is running out and Joshua turns to God and asks for help: "Sun, stand thou still upon Gibeon; and thou, Moon, in the Valley of Ajalon." God responds. "So the sun stood still in the midst of heaven, and hastened not to go down about a whole day. And there was no day like that, before it or after it, that the LORD hearkened unto the voice of a man: for the LORD fought for Israel."

The nature of Joshua's miracle is somewhat ambiguous. Yet it is clear that the day was miraculously long (for example, in the Babylonian Talmud, estimates of the length of the daylight range from 24 to 48 hours, depending on the interpretation of the word 'day' - namely, whether it means the length of daylight or a full day - and on the interpretation of the expression 'hasten not to go down"10). A straightforward interpretation of the miracle is that the Earth stopped rotating about its axis at noon for a length of time, then rotated much slower than normal, and finally, a whole day later, returned to its regular rotation. Does this miracle involve a violation of laws of nature?

Larmer presupposes that all miracles could be accounted for by divine interventions that leave the laws of nature intact. This is a substantial presupposition that needs some argumentation. Consider, for example, a miracle in which God makes some macroscopic objects move superluminally (faster-than-light), and suppose that the laws of nature prohibit superluminal motion (Relativity Theory is commonly taken to prohibit this kind of motion). Such a miracle would violate laws of nature. More generally, laws of nature and initial conditions jointly exclude the possibility of certain facts, and accordingly miracles that involve supernatural intervention to create those facts would result in the violation of laws of nature. As we shall see, the supernatural model of miracles requires such violations in the case of Joshua's miracle.

Larmer assumes a model in which the physical universe is an 'open system', so that God performs miracles by supernatural intervention to create facts that do not follow from the natural evolution of the states of physical systems. Alvin Plantinga assumes a similar model. ${ }^{11}$ In Joshua's miracle, the focus is on supernatural intervention to create new facts about existing systems. Such an intervention could be realized in two ways. God could create new facts about existing systems directly, i.e. by simply imposing on these systems a new physical state; or God could create new facts about existing systems indirectly, e.g. by creating ex nihilo new physical systems that would interact with the existing ones. Let us consider the two options in turn. In Joshua's miracle, the sudden stop in the Earth's rotation and the return to normal rotation both involve large changes in the Earth's angular momentum. Like other actual physical systems the Earth is not isolated from the rest of the universe, and like other physical systems it is subject to conservation laws. Conservation laws entail that any changes in the Earth's conserved quantities must be accounted for by the Earth's physical interactions with its physical environment. Once we take into account the influence that the physical interactions 
between the Earth and its physical environment have on the Earth's conserved quantities, and we discount the amounts exchanged with the environment, the Earth's conserved quantities should remain unchanged. Any change in a conserved quantity that is not due to interactions between the Earth and its physical environment would be tantamount to a violation of the corresponding conservation law. The implication is that if the sudden decrease and increase in the Earth's angular momentum were due to direct supernatural interventions that sanctioned new angular momenta, such that these changes did not result from physical interactions between the Earth and its physical environment, then there would be violations of the conservation of angular momentum. From the perspective of modern physics, the question whether such changes in the Earth's angular momentum are spontaneous or due to God's supernatural intervention is immaterial - in either case there would be violations of conservation of angular momentum - and the assumption that the universe is open to God's intervention is irrelevant.

Joshua's miracle would involve a violation of conservation laws even if God intervened to change the Earth's angular momentum indirectly, e.g. by creating ex nihilo new physical systems that would interact with the Earth. Such a creation would violate the principle of conservation of energy, as the newly created systems would increase the total energy of the subsystems of the universe that include them, and this increase would not be accounted for by physical interactions between these subsystems and other subsystems of the universe. Further, if the interactions between these newly created physical systems and the Earth were to induce the required changes in the angular momentum of the Earth, other laws of nature would have to be violated. Consider the sudden and dramatic change in the Earth's angular momentum that would result from stopping or substantially slowing the Earth's rotation about its axis. Such a change could be caused by dissipative forces (like, for example, friction ${ }^{12}$ ) or collision with massive objects. As means of inducing the required changes in the Earth's angular momentum, both options would be disastrous for the Earth and its inhabitants. Thus, if either of them were to produce Joshua's miracle, there would have to be substantial violations of laws of nature in order to circumvent such disasters. In fact, a dramatic change in the Earth's angular momentum would cause disasters even if it were induced by direct, rather than indirect, supernatural intervention. Thus, there would have to be substantial violations of laws of nature to circumvent disasters in this case as well. Yet, such additional violations of laws could be avoided if God intervened directly both to change the Earth's angular momentum and to leave intact the state of the Earth and its inhabitants.

It is also easy to see that creating facts by supernatural intervention (directly or indirectly) would involve another kind of violation of laws: the violation of dynamical laws (i.e. laws that govern or describe the time evolution of the states of physical systems). Indeed, the state of the solar system during Joshua's miraculous day would be different from the state that is dictated by the dynamical laws of Newtonian physics and earlier states of the solar system.

Larmer bases his argument for the compatibility of supernatural miracles with science on the claim that the idea that the material universe is open to God's supernatural intervention is compatible with modern physics. ${ }^{13}$ Plantinga appeals to a similar argument in the context of classical (deterministic) physics. ${ }^{14}$ Plantinga also argues that in the context of quantum mechanics "there seems to be even less reason to see special divine action in the world as somehow incompatible with science." ${ }^{\prime 5}$ His line of reasoning is the 
following. Standard quantum mechanics portrays the universe as indeterministic, so that the same past may be compatible with different possible futures. The probabilities of future possibilities are determined by systems' states (i.e. their wave functions) according to Born's rule. Born's rule assigns very low probabilities to various possible, curious configurations of particles, and Plantinga claims that "clearly miracles (parting the waters, rising from the dead, etc.) are not incompatible with these assignments." Further, he argues that in 'collapse' interpretations of quantum mechanics, such as those of Ghirardi, Rimini and Weber (GRW) ${ }^{16}$, "there is plenty of room for divine activity. Indeed, God could actually be the cause of the collapses [of systems' wave functions], and of the way in which they occur."17

Questions concerning the motion of the Earth are almost always analyzed within the framework of classical physics. That is why in my analysis of Joshua's miracle I did not appeal to quantum mechanics. So focusing first on classical physics, it is not difficult to see that the assumption that the physical universe is open to God's supernatural intervention does not spare the substantial violations of laws of nature that Joshua's miracle requires.

Things are much more complicated and controversial in the context of quantum mechanics. For one thing, standard quantum mechanics does not account for gravitational phenomena, and quantum gravity, the field of study that is supposed to account for such phenomena in the quantum realm, is a work in progress rather than a solid theory. For another, while quantum mechanics is instrumentally very successful, it is plagued with fundamental interpretational problems, such as the infamous 'measurement problem'18 and the related problem of accounting for the classical-like behaviour of macroscopic systems. Thus, the implications of quantum mechanics for classical-like phenomena, like the Earth's rotation, are not clear cut. Space is too short to discuss these difficult issues here, though I think that Plantinga's claim that quantum mechanics renders possible miracles like the rising from the dead, is highly disputable. In any case, returning to Joshua's miracle, it is doubtful that the shift from the classical to the quantum realm would be of any help. Any adequate quantum theory would have to reproduce the classical-like behaviour of macroscopic systems like the Earth, and so it is difficult to see how an appeal to quantum mechanics could dispense with the substantial violations of laws of nature that this miracle requires. Further, even if we grant for the sake of argument Plantinga's claim that Born's rule assigns some low probability to miraculous events like the ones mentioned above, his reasoning will still fail to support the claim that supernatural miracles are compatible with modern science. If as a matter of sheer chance an unlikely miraculous event were to be realized, that would not support the supernatural model of miracles. On the other hand, if God intervened to realize the event, so that its occurrence would not be a matter of sheer chance, then the intervention would involve a violation of laws of nature. Indeed, an example of such a violation is Plantinga's suggestion that in collapse interpretations, like the GRW collapse models, God could cause collapses of wave functions that would bring about miracles. In the GRW models, collapses of wave functions are initiated randomly and spontaneously, and they are governed by dynamical laws. Accordingly, God's intervention to cause collapses and/or govern the way they unfold would be tantamount to a violation of the theory's dynamical laws. 


\section{The supernatural model of miracles, naturalism and modern science}

I have argued above that the prospects of Larmer's and Plantinga's strategies for reconciling the supernatural model of miracles with modern science are dim. In these strategies Larmer and Plantiga in effect presuppose that in order to demonstrate that science is compatible with the supernatural model of miracles, it is necessary to show that supernatural miracles could be integrated into scientific explanations. The problem is that in the framework of modern science, there is no place for supernatural miracles, and the scientific criteria for evidential support are bound to undermine any claims for the existence of such events. Thus, supernatural miracles are necessarily unscientific. That is not to deny that if a supernatural miracle were to happen, it could become a subject for scientific investigation. If such a miracle were to happen, modern science would misconstrue it for a natural phenomenon. That is, science would treat it as an unfamiliar natural phenomenon, which has to be accounted for either by showing that it is somehow compatible with the accepted scientific laws, or by changing these laws. This is the way of modern science. Things were different a few centuries ago, when the existence and nature of God were relevant and important for the explanation of physical facts. Thus, to take a notable example, Newton's natural philosophy made space for supernatural intervention in the universe.

Does all this mean that modern science entails the impossibility of supernatural miracles? Not necessarily. Arguably, modern science is confined to natural phenomena, and accordingly supernatural miracles fall outside its boundaries. Indeed, a popular naturalist stance has it that the domain of modern science is universal, maintaining that natural phenomena exhaust all possible phenomena. If one resists this stance and interprets the jurisdiction of science as limited to natural phenomena, then the fact that supernatural miracles violate scientific laws does not entail the impossibility of such miracles. According to this interpretation, modern science under the above naturalist stance entails the impossibility of supernatural miracles by extending science's jurisdiction beyond its constituted framework. Sill, even such anti-naturalist position would not be sufficient to ease the tension between the supernatural model of miracles and modern science.

Acknowledgments: For comments and discussions on earlier versions of this paper, I am very grateful to Chris Belanger, Delia Gavrus, Yiftach Fehige, Paul Greenham and Lee Smolin.

\footnotetext{
${ }^{1}$ Robert Larmer, "Miracles, Divine Agency, and the Laws of Nature", Toronto Journal of Theology 27, no. 2 (2011): 267-290.

${ }^{2}$ Ibid., 272.

${ }^{3}$ Ibid., 282.

${ }^{4}$ Ibid., 282-283.

${ }^{5}$ Ibid., 283.
} 
${ }^{6}$ Ibid., 283.

${ }^{7}$ Ibid., 284. Larmer argues that although the principle of conservation of energy applies only to causally isolated systems and causally isolated systems may not exist, the principle is not vacuous. His argument relies on an analogy between ideal gas laws and conservation laws. "Ideal gas laws convey genuine information - that to the extent a particular gas resemble an ideal gas, it will behave in such-and-such a way. Similarly, even though there may exist in reality no completely isolated system, the claim that energy is conserved in an isolated system allows us to predict that, to the extent that a system is causally isolated, its energy will be conserved." ${ }^{8}$ Ibid., 284.

${ }^{9}$ Book of Joshua, Chapter 10: 12-14, King James version. ${ }^{10}$ Babylonian Talmud, Tractate Avodah Zarah, Folio 25a.

${ }^{11}$ Alvin Plantinga, "What is 'Intervention'?”, Theology and Science 6, no. 4 (2008): 374380; Alvin Plantinga, "Religion and Science", The Stanford Encyclopedia of Philosophy (Summer 2010 Edition), Edward N. Zalta (ed.), URL =

$<$ http://plato.stanford.edu/archives/sum2010/entries/religion-science/>: Section 3.2.

${ }^{12}$ Due to tidal friction, the Earth's angular momentum is continuously decreased by a very small amount, and accordingly its rotation is slowed by 2.3 milliseconds per day per century.

${ }^{13}$ Larmer, "Miracles", 282-284.

${ }^{14}$ Plantinga, "Intervention", 374-80 and Plantinga, "Religion", Section 3.2.

${ }^{15}$ Plantinga, "Religion", Section 3.2.

${ }^{16}$ For a review of 'collapse' interpretations of quantum mechanics, see Giancarlo Ghirardi, "Collapse Theories", The Stanford Encyclopedia of Philosophy (Winter 2011

Edition), Edward N. Zalta (ed.), forthcoming URL =

$<$ http://plato.stanford.edu/archives/win2011/entries/qm-collapse/>

${ }^{17}$ Plantinga, "Religion", Section 3.2.

${ }^{18}$ See, for example, Henry Krips, "Measurement in Quantum Theory", The Stanford Encyclopedia of Philosophy (Fall 2008 Edition), Edward N. Zalta (ed.), URL = $<$ http://plato.stanford.edu/archives/fall2008/entries/qt-measurement/>. 